\title{
TRATAMENTO HIDROTÉRMICO NA MANUTENÇÃO DA QUALIDADE PÓS-COLHEITA DE MARACUJÁ-AMARELO ${ }^{1}$
}

\author{
ANDRÉ JOSÉ DE CAMPOS ${ }^{2}$, LUCIANA MANOEL ${ }^{2}$, ERVAL RAFAEL DAMATTO JÚNIOR ${ }^{2}$, \\ ROGÉRIO LOPES VIEITES ${ }^{3}$, SARITA LEONEL ${ }^{4}$, REGINA MARTA EVANGELISTA ${ }^{3}$
}

\begin{abstract}
RESUMO - Objetivando avaliar o efeito da temperatura de imersão na manutenção da qualidade pós-colheita de frutos de maracujá-amarelo, instalou-se na FCA/UNESP este experimento, composto pelos seguintes tratamentos: T1 (testemunha); $\mathrm{T} 2\left(35^{\circ} \mathrm{C}\right.$ por 2 horas); $\mathrm{T} 3\left(35^{\circ} \mathrm{C}\right.$ por 4 horas); T4 $\left(43^{\circ} \mathrm{C}\right.$ por 2 horas); $55\left(43^{\circ} \mathrm{C}\right.$ por 4 horas); $66\left(53^{\circ} \mathrm{C}\right.$ por 2 horas $)$; $77\left(53^{\circ} \mathrm{C}\right.$ por 4 horas $)$, sendo os frutos mantidos em câmaras BOD a $12 \pm 1{ }^{\circ} \mathrm{C} \mathrm{e}$ $80-90 \%$ UR. A cada três dias, foram retiradas amostras dos tratamentos para as seguintes análises: Grupo destrutivo - pH, firmeza, sólidos solúveis (SS), acidez titulável (AT), relação (SS/AT), rendimento de polpa e vitamina C; e para o grupo-controle determinaram-se perda de massa e coloração da casca. Com base nos resultados obtidos, os tratamentos hidrotérmicos dos frutos, com temperaturas menores, como é o caso do T2 e T3, apresentaram frutos com menor perda de massa, melhor manutenção da coloração, boa manutenção da firmeza da casca e teores razoáveis de vitamina $\mathrm{C}$, enquanto as temperaturas mais elevadas causaram danos à aparência dos frutos (queima da casca) e reduziram os teores de vitamina $\mathrm{C}$ na polpa.
\end{abstract}

Termos para indexação: conservação, temperatura, Passiflora edulis Sims f. flavicarpa Deg.

\section{HYDROTHERMAL TREATMENT ON THE MAINTENANCE OF POSTHARVEST QUALITY OF PASSION FRUIT}

ABSTRACT - To assess the effects of immersion temperature on the maintenance of postharvest quality of passion fruit, an experiment was installed in FCA/UNESP. It was composed of seven treatments: T1 (control), T2 ( $35^{\circ} \mathrm{C}$ for 2 hours), $\mathrm{T} 3\left(35^{\circ} \mathrm{C}\right.$ for 4 hours), $\mathrm{T} 4$ ( $43^{\circ} \mathrm{C}$ for 2 hours), $\mathrm{T} 5$ ( $43^{\circ} \mathrm{C}$ for 4 hours), $\mathrm{T} 6\left(53^{\circ} \mathrm{C}\right.$ for 2 hours $), \mathrm{T} 7\left(53^{\circ} \mathrm{C}\right.$ for 4 hours). The fruits were maintained in BOD chambers at $12 \pm 1{ }^{\circ} \mathrm{C}$ and $80-90 \%$ RH. Samples of each treatment were collected every other three days. It was analyzed: Destructive group - pH, firmness, soluble solids (SS), titratable acidity (TA), ratio (SS/TA), pulp yield and vitamin $\mathrm{C}$, as well as mass loss and peel color were determined for the control group. According to the results, lower temperatures treatments, such as T2 and T3, showed fruit with less mass loss, best color maintenance, good firmness maintenance and reasonable vitamin $\mathrm{C}$ content. Whereas higher temperatures caused damages to the appearance of the fruit (burned peels) and reduced vitamin $\mathrm{C}$ content in the pulp.

Index terms: conservation, temperature, Passiflora edulis Sims f.flavicarpa Deg.

\section{INTRODUÇÃO}

O maracujá-amarelo ou maracujá-azedo (Passiflora edulis Sims f. flavicarpa Deg.) é nativo da América do Sul e amplamente cultivado em países tropicais e subtropicais, sendo o Brasil um dos principais produtores desta fruta. A cultura do maracujazeiro no Brasil tem grande importância pela qualidade de seus frutos, ricos em sais minerais e vitaminas, sobretudo A e C (Lima, 2002), sendo que seu cultivo vem se expandindo nos vários Estados brasileiros, havendo maior preocupação com o pós-colheita, pois o produto é perecível e sofre murcha rapidamente.

Os frutos apresentam enrugamento da casca devido ao processo de senescência, mesmo ainda quando a polpa está em boas condições para consumo, sendo por este motivo desvalorizados. Para evitar problemas de aceitação no mercado, devem ser comercializados logo após a colheita. Como alternativa para aumentar a vida pós-colheita dos frutos, deve-se atentar para a qualidade inicial do produto e para o emprego de técnicas pós-colheita que aumentem sua vida de prateleira, tais como o tratamento com água quente (tratamento hidrotérmico), além das condições de armazenamento, transporte e distribuição.

O ponto de colheita para o maracujá-amarelo é determinado quando os frutos começam a cair no chão, o que os torna suscetíveis ao apodrecimento e ao ataque de pragas que depreciam sua aparência e diminuem sua durabilidade; desse modo, devem ser comercializados ou armazenados de forma adequada, imediatamente após sua coleta no campo, para que não haja prejuízo na sua comercialização.

A boa conservação dos frutos por um período mais longo é de fundamental importância para a comercialização eficiente do produto destinado ao mercado de frutas frescas e traz benefícios para toda a cadeia de produção. Assim, após a colheita, os frutos devem ser lavados, secados, tratados, classificados e embalados de acordo com os padrões estabelecidos pelo programa brasileiro de melhoria dos padrões comerciais e embalagens de hortigranjeiros (Lima, 2002).

Os frutos podem ser armazenados em ambiente refrigerado com temperatura de aproximadamente $10^{\circ} \mathrm{C}$ e com umidade relativa entre 80 a 85\%, por um período de até 30 dias (Frutiséries, 1998; Lima \& Cardoso, 1997).

O presente trabalho teve como objetivo avaliar o efeito da temperatura de imersão na manutenção da qualidade pós-colheita de frutos de maracujá-amarelo.

\section{MATERIAL E MÉTODOS}

O maracujá foi cultivado no pomar do Departamento de Produção Vegetal - Horticultura da Faculdade de Ciências Agronômicas/ UNESP, Câmpus de Botucatu-SP, que tem como coordenadas geográficas: $22^{\circ} 52^{\prime} 47^{\prime \prime}$ latitude $\mathrm{S}, 48^{\circ} 25^{\prime} 12^{\prime \prime}$ longitude $\mathrm{W}$ e altitude de $810 \mathrm{~m}$ (Tubelis \& Salibe, 1989). Os frutos foram colhidos quando atingiram o ponto de maturação fisiológica, pela manhã, e levados ao laboratório de Frutas e Hortaliças do Departamento de Gestão e Tecnologia Agroindustrial da mesma Instituição.

$\mathrm{Na}$ seleção, foram descartados os frutos que apresentaram algum dano mecânico, defeitos e sintomas de doenças, posteriormente lavados em água corrente e submetidos aos seguintes tratamentos: T1 (testemunha); $\mathrm{T} 2$ (banho-maria a $35^{\circ} \mathrm{C}$ por 2 horas); T3 (banho-maria a $35^{\circ} \mathrm{C}$ por 4 horas); $\mathrm{T} 4$ (banho-maria a $43^{\circ} \mathrm{C}$ por 2 horas); T5 (banho-

\footnotetext{
(Trabalho 156/2004). Recebido: 11/11/2004. Aceito para publicação: 03/11/2005.

2 Eng. Agr. Doutorando em Agronomia/FCA/UNESP. Cx postal: 237, Cep: 18603-970. Botucatu-SP. Fone: (14) 3811-7172. Endereço eletrônico: ajc@fca.unesp.br, lucimanoel@fca.unesp.br, ervaljr@fca.unesp.br.

${ }^{3}$ Prof. Dr. Departamento de Gestão Agroindustrial/FCA/UNESP. Cx postal: 237, Cep: 18603-970. Botucatu-SP. Fone: (14) 3811-7172. Endereço eletrônico: vieites@fca.unesp.br.

${ }^{4}$ Prof. Dr. Departamento de Produção Vegetal/FCA/UNESP. Cx postal: 237, Cep: 18603-970. Botucatu-SP. Fone: (14) 3811-7172. Endereço eletrônico: sarinel@fca.unesp.br.
} 
maria a $43^{\circ} \mathrm{C}$ por 4 horas); T6 (banho-maria a $53^{\circ} \mathrm{C}$ por 2 horas); T7 (banho-maria a $53^{\circ} \mathrm{C}$ por 4 horas). Os tratamentos foram mantidos em câmaras BOD, no período de 17 a 30 de janeiro de 2003, com $12 \pm 1{ }^{\circ} \mathrm{C} \mathrm{e}$ $80-90 \%$ UR.

A cada três dias, foram retiradas amostras dos tratamentos para análise das seguintes variáveis:

Grupo destrutivo: a) $\mathrm{pH}$, realizado por potenciometria, utilizando-se do potenciômetro ANALYSER - modelo pH 300, conforme técnica descrita pelo Instituto Adolfo Lutz, 1985; b) análise de firmeza, medida em três pontos, através do Texturômetro Stevens-LFRA Texture Analyser: Estados Unidos, com ponta de prova TA 9/1000, e velocidade de penetração de $2 \mathrm{~mm} / \mathrm{s}$. Os dados foram expressos em grama-força ( $\mathrm{g} /$ f); c) sólidos solúveis, retirando-se uma alíquota do suco da fruta para leitura refratométrica direta em graus Brix, em três amostras, com o refratômetro tipo Abbe, marca ATAGO - N1: Japão, conforme metodologia de Tressler \& Joslyn, 1961; d) acidez titulável, determinada por titulação feita com solução de hidróxido de sódio $(\mathrm{NaOH}) 0.1 \mathrm{~N}$, utilizando $5 \mathrm{~g}$ do suco, diluídos em 100ml de água destilada, em três amostras, conforme recomendações do Instituto Adolfo Lutz, 1985, sendo os resultados expressos em gramas de ácido cítrico/100g de polpa; e) relação entre os "sólidos solúveis" e a "acidez titulável" (SS/AT); f) rendimento de polpa obtido pela diferença entre o peso do fruto e da casca; g) vitamina $\mathrm{C}$, através da metodologia da titulação com iodeto de potássio, de acordo com metodologia do Instituto Adolfo Lutz, 1985

Grupo-controle: a) perda de massa, obtida em porcentagem por pesagem direta (considerando o peso inicial de cada unidade). A balança utilizada foi da marca Owalabor - carga máxima de $2000 \mathrm{~g}$ e divisão de $10 \mathrm{mg}$; b) coloração da casca, pela avaliação de coloração baseada numa escala subjetiva de notas, variando de 1 a 5 , sendo: $1=$ totalmente verde; 2 = mais verde que amarelo; 3 = partes iguais de verde e amarelo; $4=$ mais amarelo que verde; $5=$ totalmente amarelo.

$\mathrm{O}$ delineamento estatístico empregado foi o inteiramente casualizado, com esquema fatorial ( $7 \times 5$ ), ou seja, 7 tratamentos e 5 dias de amostragem, sendo que, para o grupo destrutivo e o grupo-controle, foram efetuadas, 3 e 10 repetições, respectivamente. A análise de variância foi realizada em todos os parâmetros, e as médias foram comparadas pelo Teste de Tukey, ao nível de 5\% de probabilidade (Gomes, 1987).

\section{RESULTADOS E DISCUSSÃO}

Para perda de massa, constatou-se diferença significativa em todos os tratamentos, evidenciando a menor perda no T1 (testemunha) e $\mathrm{T} 2\left(35^{\circ} \mathrm{C}\right.$ por 2 horas). Nos tratamentos com temperaturas mais elevadas $\left(43^{\circ} \mathrm{C}\right.$ e $\left.53^{\circ} \mathrm{C}\right)$, houve maior perda de massa, independentemente do tempo de imersão, como observado na Figura 1. Durante os dias de análise, houve aumento de perda de massa devido à desidratação dos frutos à medida que se aumentou o período de armazenamento. Observou-se, ainda, interação significativa entre os tratamentos e os dias de análise.

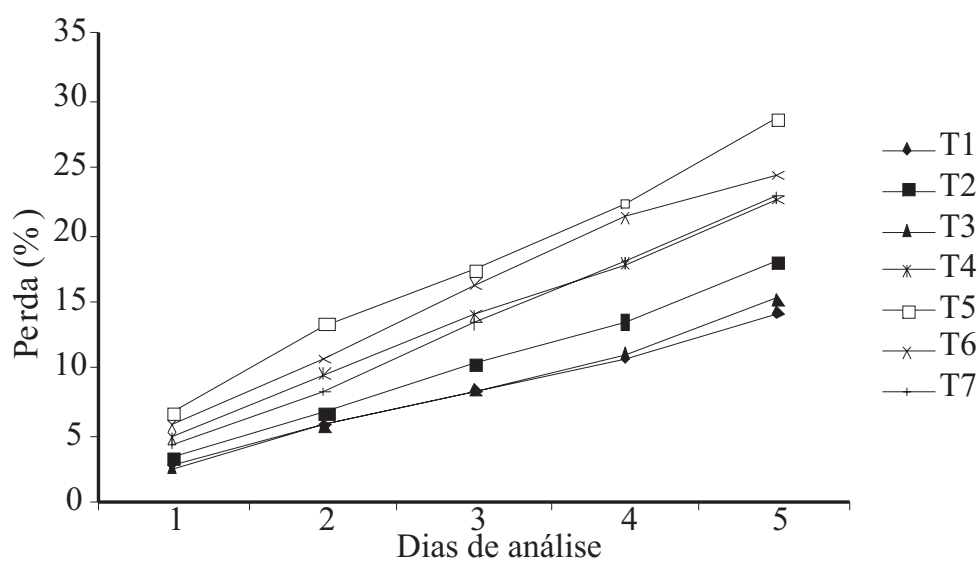

FIGURA 1 - Variação média de perda de massa (\%) dos frutos de maracujá-amarelo, nos diferentes tratamentos.
Os resultados obtidos no experimento, para coloração, estão apresentados na Figura 2. Pode-se observar através dos dados que, no $\mathrm{T} 1$ (Testemunha) e T2 $\left(35^{\circ} \mathrm{C}\right.$ por 2 horas), os frutos mantiveram sua coloração inicial após o tratamento, em comparação aos demais tratamentos. Com a elevação da temperatura de imersão, houve alteração da coloração da casca, passando de verde-clara para amarelo-clara, podendo-se relacionar à degradação da clorofila e à manifestação dos pigmentos carotenóides (Seymour et al., 1993). Observou-se, ainda, que houve queima nas cascas com as temperaturas mais elevadas. Entre os dias de avaliação, não foi observada variação significativa, porém verificou-se diferença significativa entre os fatores tratamentos $\mathrm{x}$ dias.

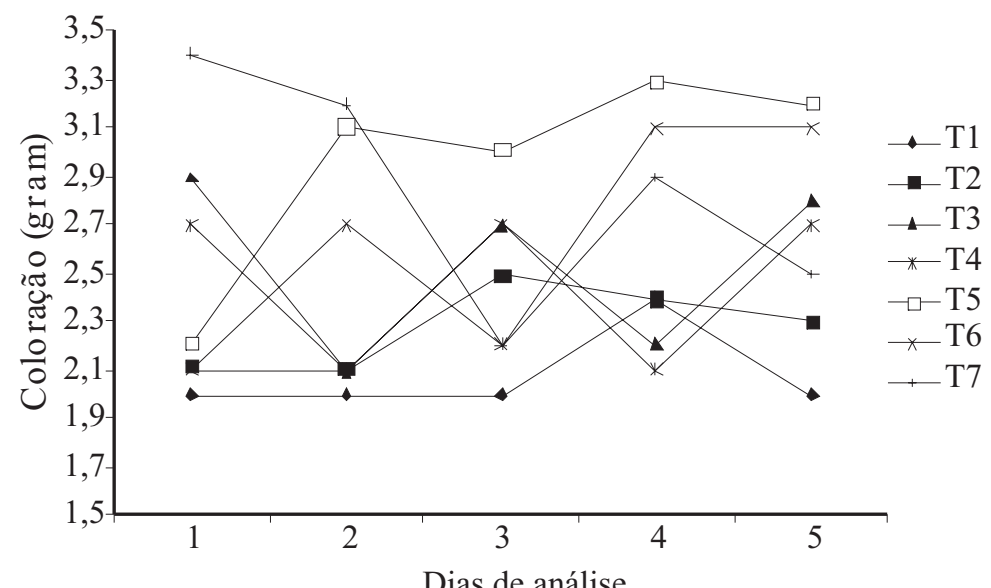

FIGURA2 - Variação média da coloração da casca dos frutos de maracujáamarelo, nos diferentes tratamentos.

Analisando-se os resultados de sólidos solúveis, pode-se verificar que não houve diferença significativa $(p>0,05)$ entre os tratamentos, dias de análise e interação entre os fatores tratamentos $\mathrm{x}$ dias, apresentando média geral de $11,36^{\circ}$ Brix. Concordando com Silva et al. (1999), que, trabalhando com fitorreguladores em maracujá-doce, observaram aumento de sólidos solúveis totais em todos os tratamentos.

Verificando as médias dos valores da acidez titulável, pode-se observar que não houve diferença significativa $(p>0,05)$ para os tratamentos, dias de análise e interação, obtendo como média geral do experimento $1,00 \pm 0,23 \mathrm{~g}$ ácido cítrico/ $100 \mathrm{~g}$ de polpa.

$\mathrm{O}$ mesmo ocorreu para os valores da relação $\mathrm{SS} / \mathrm{AT}$, não havendo diferença significativa $(\mathrm{p}>0,05)$ para os tratamentos, dias de análise e interação entre fatores (tratamentos x dias) e apresentando média geral de $11,67 \pm 2,82$.

Nos valores médios de $\mathrm{pH}$, observamos que não houve diferença significativa para os tratamentos e para os dias de análise, obtendo como média geral 3,01 $\pm 0,28$, mas, em relação à interação entre os fatores tratamentos x dias, pode-se observar que houve diferença significativa. Estes valores estão próximos aos encontrados por Resende et al. (2001), que obtiveram valores médios de $\mathrm{pH}$ iguais a 2,53.

Analisando as médias dos valores de firmeza (Figura 3) entre os tratamentos, verificamos que o tratamento T1 (testemunha) mostrou os maiores valores em relação aos demais; isso se deve principalmente pelo fato de que o tratamento hidrotérmico causa amolecimento da casca dos frutos, proporcionando menores valores, sendo $\mathrm{T} 6\left(53^{\circ} \mathrm{C}\right.$ por 2 horas) e $\mathrm{T} 7\left(53^{\circ} \mathrm{C}\right.$ por 4 horas) os tratamentos que obtiveram os valores médios de firmeza mais baixos, enquanto as médias dos valores entre os dias de análise não apresentaram diferença significativa $(\mathrm{p}>0,05)$.

Nos valores de rendimento de polpa, não houve diferença significativa $(\mathrm{p}>0,05)$ para os tratamentos e para os dias de análise. Mas, em contrapartida, proporcionou interação significativa entre os fatores $(\mathrm{p}<0,05)$, sendo o valor médio do experimento $67,51 \pm 24,68 \%$.

$\mathrm{O}$ teor de Vitamina $\mathrm{C}$ no suco é um dos principais indicadores de seu valor nutritivo. O comportamento do valor do ácido ascórbico no maracujá mostra-se no sentido de aumentar até o amadurecimento do fruto. Isto pôde ser verificado nos valores deste parâmetro entre os 
dias de análise, no qual o quarto dia proporcionou os maiores valores, diferindo estatisticamente do primeiro, segundo e quinto dias de análise, quando se encontraram os menores resultados de vitamina C. No quarto dia de análise, os frutos atingiram o seu completo amadurecimento.

Com relação aos valores médios de vitamina $\mathrm{C}$ entre os tratamentos, o T1 (testemunha) apresentou os maiores valores deste parâmetro, sendo diferente estatisticamente dos tratamentos $\mathrm{T} 2\left(35^{\circ} \mathrm{C}\right.$ por 2 horas), $\mathrm{T} 5\left(43^{\circ} \mathrm{C}\right.$ por 4 horas $), \mathrm{T} 6\left(53^{\circ} \mathrm{C}\right.$ por 2 horas $), \mathrm{T} 3\left(35^{\circ} \mathrm{C}\right.$ por 4 horas), $\mathrm{T} 7\left(53^{\circ} \mathrm{C}\right.$ por 4 horas) e $\mathrm{T} 4\left(43^{\circ} \mathrm{C}\right.$ por 2 horas $)$, como pode ser observado na Figura 4, proporcionando diferença significativa na interação dos fatores tratamentos $x \operatorname{dias}(p<0,05)$.

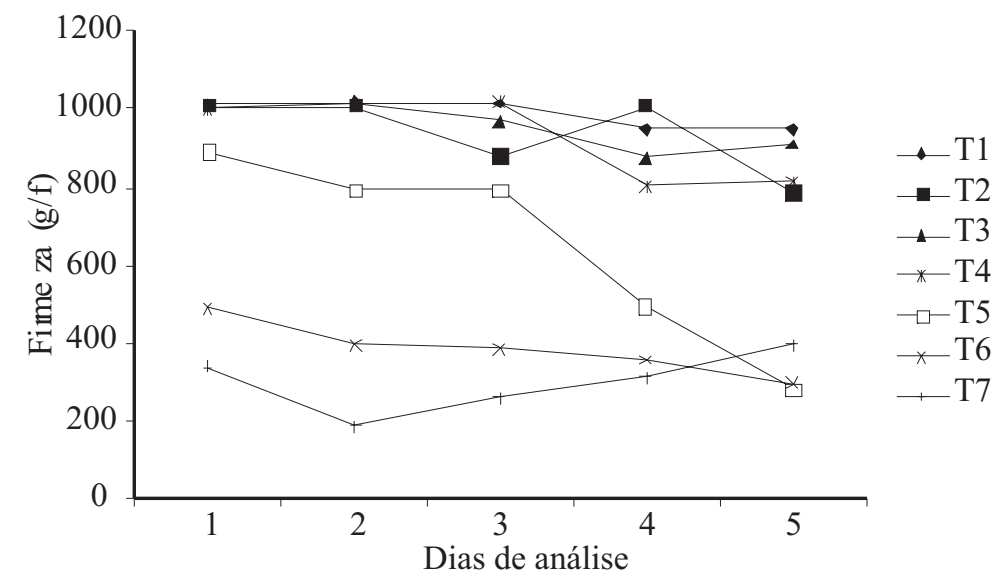

FIGURA 3 - Variação média da firmeza (g/f) de frutos de maracujáamarelo, nos diferentes tratamentos.

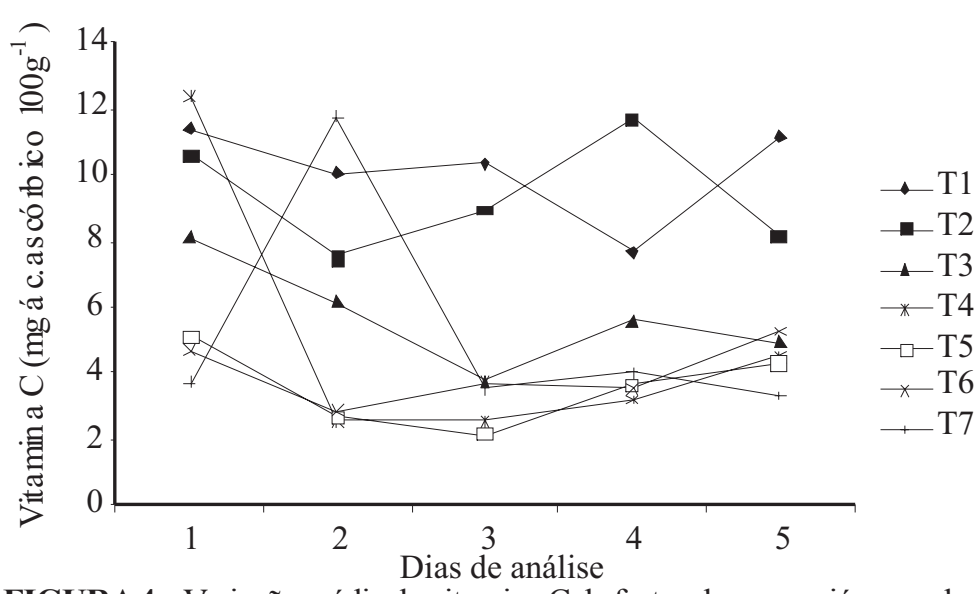

FIGURA4 - Variação média de vitamina C de frutos de maracujá-amarelo, nos diferentes tratamentos.

\section{CONCLUSÕES}

Com base nos resultados obtidos, os tratamentos hidrotérmicos dos frutos, com temperaturas menores, como é o caso do $\mathrm{T} 2\left(35^{\circ} \mathrm{C}\right.$ por 2 horas $)$ e $\mathrm{T} 3\left(35^{\circ} \mathrm{C}\right.$ por 4 horas $)$, apresentaram frutos com menor perda de massa, melhor manutenção da coloração, boa manutenção da firmeza da casca e teores razoáveis de vitamina $\mathrm{C}$, enquanto as temperaturas mais elevadas causaram danos à aparência dos frutos (queima da casca) e reduziram os teores de vitamina $\mathrm{C}$ na polpa.

\section{REFERÊNCIAS}

FRUTISÉRIES. Maracujá-amarelo. Brasília: MMA, 1998. v.4

GOMES, F.P. Curso de estatística experimental. 12. ed. Piracicaba: Nobel, 1987.p. 467.

INSTITUTO ADOLFO LUTZ. Métodos físicos e químicos para a análise de alimentos. 3.ed. São Paulo, 1985. p. 533.

LIMA, A. de A. Maracujá produção: aspectos técnicos. Cruz das Almas: Embrapa Mandioca e Fruticultura, Cruz das Almas. Brasília: Embrapa Informação Tecnológica, 2002. p. 103. (Frutas do Brasil; 15).

LIMA, A. de A.; CARDOSO, C.E.L. Mercado e comercialização do maracujá-amarelo. Cruz das Almas: Embrapa-CNPMF, 1997. p. 2. (Maracujá em Foco, 3).

RESENDE, J.M.; VILAS BOAS, E.V. de B.; CHITARRA, M.I.F. Uso de atmosfera modificada na conservação pós-colheita do maracujáamarelo. Ciência Agrotécnica, Lavras, v.25, n.1, p.159-168, 2001.

SEYMOUR, G.B.; TAYLOR, J.E.; TUCKER, G.A. Biochemistry of fruit ripening. 1. ed. London: Chapman \& Hall, 1993. p. 454.

SILVA, A.P.; DOMINGUES, M.C.; VIEITES, R.L.; RODRIGUES, J.D. Fitorreguladores na conservação pós-colheita do maracujá-doce (Passiflora alata Dryander) armazenado sob refrigeração. Ciência Agrotécnica, Lavras, v.23, n.3, p.643-649, 1999.

TRESSLER, D. J.; JOSLYN, M. A. Fruits and vegetable juice processing. Westport: Connecticut AVI, 1961.p. 1.028.

TUBELIS, A.; SALIBE, A.A. Relações entre produção de laranjeira "Hamlin" e as precipitações mensais no altiplano de Botucatu. Pesquisa Agropecuária Brasileira, Brasília, v.23, p.801-806, 1989. 